\title{
JNPH
}

Volume 7 No. 2 (Oktober 2019)

(C) The Author(s) 2019

\section{HUBUNGAN PENGETAHUAN IBU TENTANG STIMULASI DENGAN \\ PERKEMBANGAN ANAK USIA 4-5 TAHUN DI PAUD BINA ANA PRASA DAN PAUD ISLAM BAITURRAHIM KABUPATEN REJANG LEBONG}

\author{
THE RELATIONSHIP BETWEEN MOTHER'S KNOWLEDGE OF STIMULATION \\ AND THE DEVELOPMENT OF 4-5 YEARS OLD CHILDREN IN BINA ANA PRASA \\ PAUD AND BAITURRAHIM ISLAMIC PAUD REJANG LEBONG DISTRICT
}

\author{
NURUL KHAIRANI, SANISAHHURI, VONI BERLINDA \\ PRODI KESEHATAN MASYARAKAT STIKES TRI MANDIRI SAKTI BENGKULU \\ JL. HIBRIDA RAYA NO. 03 KELURAHAN SIDOMULYO KOTA BENGKULU 38229 \\ Email :nrlkhairani@yahoo.com
}

\begin{abstract}
ABSTRAK
Periode penting dalam perkembangan anak adalah masa balita. Pada masa ini perkembangan kemampuan berbahasa, kreativitas, kesadaran sosial dan lain-lain berjalan sangat cepat yang dipengaruhi oleh kebutuhan dasar anak (asuh, asah, dan asih) untuk menentukan perkembangan selanjutnya. Penelitian ini bertujuan untuk mempelajari hubungan Pengetahuan Ibu tentang stimulasi dengan perkembangan anak usia 4-5 Tahun di PAUD Bina Ana Prasa dan PAUD Islam Baiturrahim Kabupaten Rejang Lebong. Jenis penelitian ini adalah Survey Analitik dengan desain Cross Sectional. Populasi dalam penelitian ini adalah seluruh ibu yang memiliki anak usia 4-5 tahun di PAUD Bina Ana Prasa dan PAUD Islam Baiturrahim tahun ajaran 2018/2019 sebanyak 52 ibu. Sampel sebanyak 52 ibu yang diambil dengan menggunakan teknik Total Sampling. Teknik analisis data dilakukan dengan analisis univariat dan bivariat dengan menggunakan uji Chi-Square $\left(\mathrm{c}^{2}\right)$. Hasil penelitian diketahui dari $52 \mathrm{ibu}$, terdapat 18 ibu $(34,6 \%)$ berpengetahuan kurang dan 31 ibu (59,6\%) yang memiliki anak dengan perkembangan sesuai dengan tahap perkembangan. Ada hubungan yang signifikan antara pengetahuan ibu dengan perkembangan anak di PAUD Bina Ana Prasa dan PAUD Islam Baiturrahim Kabupaten Rejang Lebong dengan kategori hubungan kuat. Diharapkan bagi PAUD agar selalu dapat meningkatkan kualitas pelayanan, khususnya pemantauan perkembangan balita dengan upaya melakukan deteksi dini penyimpangan perkembangan anak secara rutin dan melakukan kegiatan yang merangsang stimulasi anak.
\end{abstract}

Kata Kunci: pengetahuan ibu, perkembangan anak, stimulasi perkembangan

\begin{abstract}
An important period in child development is the toddler period, at this time the development of language skills, creativity, social awareness and others goes very fast that affected by the basic needs of the children (fostering, sharpening, and compassion) to determine the next development even. The purpose of this research was to study the relationship between mother's knowledge of stimulation and development of children aged 4-5 years in Bina Ana Prasa PAUD and Baiturrahim Islamic PAUD, Rejang Lebong District. Type of this research was Survey
\end{abstract}


Analitytic with Cross Sectional design. The population in this study was all mothers who have children aged 4-5 years in Bina Ana Prasa PAUD and Baiturrahim Islamic PAUD in the 2018/2019 school year, as many as 52 mothers. Sample were taken using a Total Sampling technique amount to 52 mothers. Analysis were performed with univariate and bivariate analysis with Chi-Square test $\left(\mathrm{c}^{2}\right)$. The results of the study revealed that of the 52 mothers of toddlers, there were 18 mothers $(34.6 \%)$ who had lacking knowledge and 31 mothers $(59.6 \%)$ who had children with development in accordance with the stages of development. There was a significant relationship between mother's knowledge and child development in Bina Ana Prasa PAUD and Baiturrahim Islamic PAUD, in Rejang Lebong District, with a strong relationship category. It is expected that PAUD can always improve the quality of services, especially monitoring the development of toddlers by efforts to detect early deviations of child development routinely, and conduct activities that stimulate child stimulation.

\section{Keywords: children's development, mother's knowledge, stimulation development}

\section{PENDAHULUAN}

Pembangunan kesehatan sebagai bagian dari upaya membangun manusia seutuhnya antara lain diselenggarakan melalui upaya kesehatan anak yang dilakukan sedini mungkin sejak anak masih didalam kandungan. Upaya kesehatan yang dilakukan sejak anak masih di dalam kandungan sampai lima tahun pertama kehidupannya, ditujukan untuk mempertahankan kelangsungan hidupnya sekaligus meningkatkan kualitas hidup anak agar mencapai tumbuh kembang optimal baik fisik, mental, emosional maupun sosial serta memiliki intelejensi majemuk sesuai dengan potensi genetiknya (Kemenkes RI, 2018).

Kualitas tumbuh kembang balita di Indonesia perlu mendapat perhatian serius yaitu mendapat gizi yang baik, stimulasi yang memadai serta terjangkau oleh pelayanan kesehatan berkualitas termasuk deteksi dan intervensi dini penyimpangan tumbuh kembang. Melakukan stimulasi yang memadai artinya merangsang otak balita sehingga perkembangan kemampuan gerak, bicara dan bahasa, sosialisasi dan kemandirian pada balita berlangsung secara optimal sesuai dengan umur anak. Melakukan deteksi dini penyimpangan tumbuh kembang artinya melakukan skrining atau mendeteksi secara dini adanya penyimpangan tumbuh kembang balita termasuk menindaklanjuti setiap keluhan orang tua terhadap masalah tumbuh kembang anaknya. Kegiatan stimulasi, deteksi dan intervensi dini penyimpangan tumbuh kembang balita yang menyeluruh dan terkoordinasi diselenggarakan dalam bentuk kemitraan antara keluarga, orang tua, pengasuh anak dan anggota keluarga lainnya (Kemenkes RI 2018).

Kebutuhan dasar awal untuk tumbuh kembang yaitu asuh, asih dan asah. Stimulasi perkembangan merupakan bagian dari kebutuhan dasar anak yaitu asah. Dalam perkembangan anak terdapat masa kritis di saat itu diperlukan rangsangan atau stimulasi yang berguna agar potensi anak berkembang. Anak yang memperoleh stimulasi terarah akan lebih cepat berkembang dibanding dengan anak yang kurang mendapat stimulasi. Dengan mengasah kemampuan anak secara terus-menerus, maka kemampuan anak akan semakin meningkat (Soetjiningsih 2013).

Menurut Soetjiningsih (2013), beberapa gangguan perkembangan anak antara lain gangguan bicara dan bahasa yang diperkirakan angka kejadiannya berkisar 1,0\%-32,0\%, cerebral palsy sekitar $1-5$ per 1000 anak, down sindrom yaitu 1 per 1000 anak, retardasi mental sekitar 0,3\%-0,4\%, gangguan pemusatan perhatian dan hiperaktivitas sebesar 4,0\%-12,0\%. Untuk autis belum ada angka kejadian yang pasti, hanya dari pengamatan beberapa ahli didapatkan kecenderungan peningkatan kasus yang ditangani. Penelitian yang dilakukan di 
Jepang terhadap 21.610 anak yang diikuti sejak lahir sampai umur 3 tahun didapatkan 1,3 kasus autis per 1000 anak. Hasil yang serupa didapatkan di Swedia, yaitu sekitar 1-2 per 1000 anak menderita autis (Soetjiningsih, 2013).

Menurut Soetjiningsih, (2013), lebih dari dua dekade, diketahui bahwa masalah developmental, behavioral, dan psikososial merupakan "new morbidity". Masalah ini disebabkan oleh adanya perubahan pesat di bidang pediatrik dan tingginya prevalensi anak-anak yang mengalami masalah perkembangan. Angka kejadian penyimpangan perkembangan pada anak diseluruh dunia sekitar 10,0\%-17,0\%. Data yang didapat dari Kemenkes RI tahun 2010 juga menunjukkan 48,0\% anak Indonesia mengalami keterlambatan dalam perkembangan dan $23,0 \%$ diantaranya terjadi karena keterlambatan atau kesalahan dalam memberikan stimulasi (Kemenkes RI, 2010).

Cakupan deteksi tumbuh kembang anak balita dan pra sekolah adalah cakupan anak umur 16 tahun yang dideteksi kesehatan dan tumbuh kembangnya sesuai dengan standar oleh tenaga kesehatan (dokter, bidan dan perawat). Program pemerintah untuk memberikan pelayanan deteksi dini tumbuh kembang pada anak balita dan anak pra sekolah sejak dini akan merangsang perkembangan anak di kemudian hari dan dapat mendeteksi anak jika terdapat penyimpangan. Indikator keberhasilan tahun 2018 diharapkan 90\% dari balita dan anak pra sekolah terjangkau oleh kegiatan stimulasi dan intervensi dini penyimpangan tumbuh kembang sehingga diharapkan para ibu memberikan stimulasi perkembangan bagi anaknya dan datang ke tenaga kesehatan terdekat untuk mendeteksi dini tumbuh kembang anak nya. (Kemenkes RI, 2018).

Berdasarkan penelitian yang dilakukan Kusuma (2012) tentang hubungan pengetahuan ibu dengan perkembangan motorik halus balita di wilayah kerja Puskesmas Penumping Surakarta mengatakan bahwa orang tua memerlukan sejumlah pengetahuan teoritis tentang urutan perkembangan dan secara khusus orang tua perlu menyadari bahwa perkembangan berfluktuasi antara periode kestabilan dan ketidakstabilan. Pengetahuan ini akan membantu orang tua menjadi sadar dan paham. Hal ini menunjukkan bahwa pengetahuan tersebut akan membawa ibu untuk berpikir dan berusaha supaya anaknya tidak mengalami penyimpangan perkembangan. Dalam komponen ini komponen emosi dan keyakinan ikut bekerja sehingga ibu berniat akan melakukan stimulasi/rangsangan terhadap perkembangan anak dan pada akhirnya ibu melakukan tindakan stimulasi/rangsangan perkembangan anak.

Hasil penelitian Hotmaria (2010). menunjukkan bahwa terdapat hubungan pengetahuan ibu tentang stimulasi perkembangan dengan perkembangan anak usia 3-5 tahun di kelurahan Kwala Bekala Pada penelitian yang dilakukan oleh Azizah (2012) tentang gambaran stimulasi perkembangan oleh ibu terhadap anak usia prasekolah di TKIT Cahaya Ananda Depok terdapat hubungan yang bermakna antara pengetahuan tentang stimulasi dengan perkembangan anak. Ibu yang berpengetahuan baik tentang stimulasi, akan mengetahui adanya keterlambatan dan penyimpangan perkembangan anak dan disarankan kepada ibu untuk dapat melakukan stimulasi pada anak sehinggga dapat berkembang secara optimal.

Berdasarkan penelitian yang dilakukan Suhadah (2015), tentang hubungan tingkat pengetahuan ibu tentang stimulasi dengan perkembangan balita di Posyandu RW 06 Rejosari Rejowinangun Kota Gede Yogyakarta terdapat hubungan antara pengetahuan ibu dengan perkembangan balita 1-5. Karena pengetahuan ibu yang baik sangat erat hubungannya dengan perkembangan anak yang baik dan sebaliknya pengetahuan ibu yang kurang baik membuat perkembangan anak kurang baik dalam tahap perkembangannya (Suhadah, 2015).

Berdasarkan data dari Puskesmas Perumnas Kabupaten Rejang Lebong tahun 2018 pada 4 
PAUD diperoleh hasil, PAUD Anak Sholeh jumlah anak usia 4-5 tahun ada 28 anak dengan tingkat perkembangan meragukan ada 2 anak, PAUD Ummatan Wahidah jumlah anak usia 4-5 tahun dengan tingkat perkembangan meragukan ada 2 anak, PAUD Islam Baiturrahin jumlah anak usia 4-5 tahun ada 28 anak dengan tingkat perkembangan meragukan ada 3 anak dan 1 anak dengan tingkat perkembangan menyimpang, dan di PAUD Bina Ana Prasa jumlah anak usia 4-5 tahun ada 38 anak dengan tingkat perkembangan meragukan ada 6 anak dan 3 anak dengan tingkat perkembangan menyimpang. Dari data tersebut menunjukkan bahwa di PAUD Bina Ana Prasa dan PAUD Islam Baiturrahim terdapat cakupan tingkat perkembangan meragukan dan menyimpang yang tertinggi (Dinkes Kabupaten Rejang Lebong, 2018)

Berdasarkan survey awal yang telah dilakukan di PAUD Bina Ana Prasa dan PAUD Islam Baiturrahim pada tanggal 08 April 2019, terdapat 56 anak PAUD di Bina Ana Prasa dan anak yang berusia 4-5 tahun sebanyak 32 anak. Dari 10 orang ibu yang memiliki anak usia 4-5 tahun, terdapat 1 anak dengan perkembangan yang menyimpang, 3 anak dengan perkembangan meragukan dan 6 anak yang sesuai dengan tahap perkembangan. Pada PAUD Islam Baiturrahim jumlah anak usia 4-5 tahun ada 20 anak dengan tingkat perkembangan meragukan sebanyak 2 anak dan 1 anak dengan tingkat perkembangan menyimpang. Berdasarkan hasil observasi dan wawancara pada 10 orang ibu di PAUD Bina Ana Prasa, terdapat 3 orang ibu yang berpengetahuan cukup dan 7 orang ibu yang berpengetahuan kurang. Pada PAUD Islam Baiturrahim terdapat 6 orang ibu yang berpengetahuan kurang dan 4 orang ibu yang berpengetahuan cukup.

Rumusan masalah dalam penelitian ini adalah "Apakah ada hubungan pengetahuan ibu tentang stimulasi dengan perkembangan anak Usia 4-5 tahun di PAUD Bina Ana Prasa dan PAUD Islam Baiturrahim Kabupaten Rejang Lebong"? Tujuan penelitian ini adalah untuk mempelajari hubungan pengetahuan ibu dengan perkembangan anak usia 4-5 Tahun di PAUD Bina Ana Prasa dan PAUD Islam Baiturrahim kabupaten Rejang Lebong.

\section{METODE PENELITIAN}

Tempat penelitian ini dilaksanakan di PAUD Bina Ana Prasa dan PAUD Islam Baiturrahim Kabupaten Rejang Lebong, yang dilaksanakan pada tanggal 21-31 Mei 2019. Jenis penelitian ini merupakan penelitian Survei Analitik dengan desain penelitian Cross Sectional. Populasi dalam penelitian ini adalah seluruh ibu yang memiliki anak usia 45 tahun di PAUD Bina Ana Prasa dan PAUD Islam Baiturrahim tahun ajaran 2018/2019 yang berjumlah 52 Ibu. Sampel penelitian adalah ibu yang memiliki anak usia 4-5 tahun di PAUD Bina Ana Prasa dan PAUD Islam Baiturrahim yang berjumlah 52 ibu. Teknik pengambilan menggunakan Total Sampling. Teknik pengumpulan data adalah data primer dan sekunder. Teknik Analisis data adalah analisis univariat untuk memperoleh distribusi dari variabel bebas (pengetahuan ibu tentang stimulasi) dan variabel terikat (perkembangan anak usia 4-5 tahun). Analisis bivariat digunakan untuk mengetahui hubungan variabel bebas dengan variabel terikat dengan menggunakan uji Chi-Square $\left(\mathrm{c}^{2}\right)$. Untuk mengetahui keeratan hubungan digunakan uji Contingency Coefficient (C).

\section{HASIL PENELITIAN}

\section{Analisis Univariat}

Analisis univariat bertujuan untuk menggambarkan distribusi frekuensi dari variabel bebas (pengetahuan ibu tentang stimulasi) dan variabel terikat (perkembangan anak) di PAUD Bina Ana Prasa dan PAUD Islam Baiturrahim Kabupaten Rejang Lebong. Hasil analisis univariat dapat dilihat pada tabel berikut ini :

Tabel 1. Distribusi Frekuensi Pengetahuan Ibu tentang Stimulasi di PAUD Bina Ana 
Prasa dan PAUD Islam Baiturrahim Kabupaten Rejang Lebong

\begin{tabular}{cccc}
\hline No. & $\begin{array}{c}\text { Pengetahuan } \\
\text { Ibu Tentang } \\
\text { Stimulasi }\end{array}$ & Frekuensi & Persentase (\%) \\
\hline 1. & Kurang & 18 & 34,6 \\
\hline 2. & Cukup & 13 & 25,0 \\
\hline 3 & Baik & 21 & 40,4 \\
\hline & Total & 52 & 100,0 \\
\hline
\end{tabular}

Berdasarkan Tabel 1 di atas diketahui bahwa dari 52 ibu di PAUD Bina Ana Prasa dan PAUD Islam Baiturrahim terdapat $18 \mathrm{ibu}$ $(34,6 \%)$ berpengetahuan kurang, $13 \mathrm{ibu}$ $(25,0 \%)$ berpengetahuan cukup dan terdapat $21 \mathrm{ibu}(40,4 \%)$ berpengetahuan baik.

Tabel 2. Distribusi Frekuensi Perkembangan anak di Di PAUD Bina Ana Prasa dan PAUD Islam Baiturrahim Kabupaten Rejang Lebong

\begin{tabular}{cccc}
\hline No. & $\begin{array}{c}\text { Perkembangan } \\
\text { Balita }\end{array}$ & Frekuensi & Persentase (\%) \\
\hline 1 & Menyimpang & 0 & 0,0 \\
\hline 2 & Meragukan & 21 & 40,4 \\
\hline 3 & Sesuai & 31 & 59,6 \\
\hline & Total & 52 & 100,0 \\
\hline
\end{tabular}

Berdasarkan Tabel 2 di atas diketahui bahwa dari 52 anak di PAUD Bina Ana Prasa dan PAUD Islam Baiturrahim, tidak terdapat anak usia 4-5 tahun yang memiliki perkembangan menyimpang, terdapat 21 (40,4\%), anak yang memiliki perkembangan meragukan, dan 31 anak (59,6\%), memiliki perkembangan sesuai dengan tahap perkembangannya.

\section{Analisis Bivariat}

Analisis ini dilakukan untuk mengetahui hubungan antara variabel bebas (pengetahuan ibu tentang stimulasi) dan variabel terikat (perkembangan anak) di PAUD Bina Ana Prasa dan PAUD Islam Baiturrahim Kabupaten Rejang Lebong. Hasil analisis bivariat dapat dilihat pada tabel berikut :
Tabel 4. Tabulasi Silang antara Pengetahuan Ibu tentang Stimulasi dengan Perkembangan Anak Usia 4-5 Tahun di PAUD Bina Ana Prasa dan PAUD Islam Baiturrahim Kabupaten Rejang Lebong

\begin{tabular}{|c|c|c|c|c|c|c|}
\hline \multirow[t]{3}{*}{$\begin{array}{c}\text { Pengetahuan } \\
\text { Ibu }\end{array}$} & \multicolumn{3}{|c|}{$\begin{array}{c}\text { Perkembangan } \\
\text { Anak }\end{array}$} & \multirow[t]{2}{*}{ Total } & \multirow{3}{*}{$p$} & \multirow{3}{*}{$C$} \\
\hline & \multicolumn{2}{|c|}{ Meragukan } & Sesuai & & & \\
\hline & $\mathrm{f}$ & $\%$ & f $\%$ & $\mathrm{f} \quad \%$ & & \\
\hline Kurang & 12 & 66,7 & $\begin{array}{ll}633,3 \\
\end{array}$ & 18100 & & \\
\hline Cukup & 7 & 53,8 & $\begin{array}{ll}646,2 \\
\end{array}$ & 13100 & 001 & 0466 \\
\hline Baik & 2 & 9,5 & 1990,5 & 21100 & & 400 \\
\hline Total & 21 & 40,4 & 3159,6 & 52100 & & \\
\hline
\end{tabular}

Berdasarkan Tabel 4 diatas dapat diketahui bahwa dari 18 ibu yang berpengetahuan kurang, terdapat $12 \mathrm{ibu}$ yang memiliki anak dengan perkembangan yang meragukan dan 6 ibu yang memiliki anak dengan perkembangan sesuai dengan tahap perkembangannya. Dari 13 Ibu yang berpengetahuan cukup, terdapat $7 \mathrm{ibu}$ yang memiliki anak dengan perkembangan yang meragukan, 6 ibu yang memiliki anak dengan perkembangan yang sesuai dengan tahap perkembangannya. Dari 21 Ibu yang berpengetahuan baik, terdapat $2 \mathrm{ibu}$ yang memiliki anak dengan perkembangan yang meragukan dan 19 ibu yang memiliki anak dengan perkembangan yang sesuai dengan tahap perkembangannya.

Untuk mengetahui hubungan pengetahuan ibu dengan perkembangan anak usia 4-5 tahun di PAUD Bina Ana Prasa dan PAUD Islam Baiturrahim digunakan uji ChiSquare (Pearson Chi Square). Hasil uji Pearson Chi Square didapat nilai exact.sig $(p)=0,001$. Karena nilai $\mathrm{p}<0,05$ maka Ho diterima dan Ha ditolak. Jadi ada hubungan yang signifikan pengetahuan ibu tentang stimuasi dengan perkembangan anak usia 4-5 tahun di PAUD Bina Ana Prasa dan PAUD Islam Baiturrahim. Hasil Uji Contingency Coeeffisient nilai $\mathrm{C}=0,466$. Karena nilai $\mathrm{C}$ $=0,466$ dekat dengan $\mathrm{C}_{\max }=0,707$. Maka hubungan pengetahuan ibu dengan perkembangan anak termasuk ke dalam kategori erat. 


\section{PEMBAHASAN}

\section{Analisis Univariat}

a. Pengetahuan Ibu Tentang Stimulasi Di PAUD Bina Ana Prasa dan PAUD Islam Baiturrahim Kabupaten Rejang Lebong

Berdasarkan hasil penelitian yang dilakukan oleh peneliti di PAUD Bina Ana Prasa dan PAUD Islam Baiturrahim dari 52 ibu, terdapat 18 ibu $(34,6 \%)$ yang berpengetahuan kurang. Berdasarkan hasil kuesioner terlihat ibu kurang mengetahui kapan sebaiknya anak diberikan rangsangan atau stimulasi, ibu belum mengerti tentang kegunaan stimulasi atau rangsangan pada anak, dan belum mengerti tentang tujuan stimulasi. Ada 13 Ibu (25,0\%) berpengetahuan cukup.

Berdasarkan hasil kuesioner terlihat ibu tidak mengetahui akibat pemberian stimulasi yang berlebihan dan masih ada ibu yang belum mengetahui tentang perkembangan motorik halus, motorik kasar, kemampuan sosialisasi dan kemandirian, serta perkembangan bahasa dan bicara. Ada $21 \mathrm{ibu}$ (40,4\%), yang berpengetahuan baik. Hal ini terlihat dari ibu mampu menjawab pertanyaan tentang pemberian stimulasi atau rangsangan pada anak, dan mengerti tentang tujuan stimulasi, ibu mengetahui tentang perkembangan motorik halus, motorik kasar, kemampuan sosialisasi dan kemandirian, dan ibu mengerti tentang perkembangan bahasa dan bicara. Masih ada ibu yang belum mengerti mengenai kegiatan atau permainan apa yang tepat untuk merangsang perkembangan sosialisasi anak.

Pengetahuan adalah hasil dari tahu dan ini terjadi setelah orang melakukan penginderaan terhadap suatu obyek tertentu melalui panca indera manusia. Pengetahuan merupakan subyek yang sangat penting untuk terbentuknya tindakan seseorang (Notoatmodjo, 2007).

Pengetahuan tentang stimulasi ini akan membantu orang tua menjadi sadar dan paham mengenai keterlambatan dalam tingkat perkembangan. Hal ini menunjukkan bahwa pengetahuan tersebut akan membawa ibu untuk berpikir dan berusaha supaya anaknya tidak mengalami penyimpangan perkembangan. Dalam komponen ini komponen emosi dan keyakinan ikut bekerja, sehingga ibu berniat akan melakukan stimulasi/rangsangan terhadap perkembangan anak dan pada akhirnya ibu melakukan tindakan stimulasi/rangsangan perkembangan anak (Soetjiningsih, 2013).

\section{b. Perkembangan Anak Usia 4-5 Tahun di PAUD Bina Ana Prasa dan PAUD Islam Biturrahim}

Berdasarkan hasil penelitian yang dilakukan oleh peneliti di PAUD Bina Ana Prasa dan PAUD Islam Baiturrahim dari 52 ibu, tidak terdapat anak dengan perkembangan menyimpang, terdapat $21 \mathrm{ibu}$ $(40,4 \%)$ memiliki anak dengan perkembangan meragukan. Hal ini terlihat dari observasi dan hasil jawaban kuesioner anak yang tidak bisa melakukan gerakan motorik kasar seperti mengayuh sepeda roda tiga, belum bisa menyusun balok dan masih terdapat anak yang tidak bisa berdiri satu kaki tanpa berpegangan, masih ada anak yang belum bisa mengancingkan bajunya sendiri dan masih ada anak yang menyebutkan nama lengkapnya tanpa di bantu.

Ada 31 anak (59,6\%) yang memiliki anak dengan perkembangan sesuai dengan tahap perkembangannya. Berdasarkan observasi peneliti terhadap anak dengan perkembangan sesuai dengan tahap perkembangan, anak dapat melakukan aspek perkembangan gerak kasar, gerak halus, bicara dan bahasa serta sosialisasi dan kemandirian dengan tepat. Hal ini terlihat dari hasil observasi dan wawancara bahwa anak dapat menyebut nama lengkapnya tanpa dibantu, anak dapat mengancingkan bajunya sendiri, anak bisa meletakkan 8 buah kubus, dan bisa menggambar seperti contoh yang diberikan.

Balita merupakan kelompok anak yang berada dalam proses pertumbuhan dan 
perkembangan yang bersifat unik, artinya memiliki pola pertumbuhan dan perkembangan fisik. Perkembangan (development) adalah bertambahnya kemampuan (skill) dalam struktur dan fungsi tubuh yang lebih kompleks, mengikuti pola yang teratur, dan dapat diramalkan, sebagai hasil dari proses pematangan (Sulistyawati, 2014). Menurut Whaley dan Wong didalam buku Septiari (2012), bahwa perkembangan menitikberatkan pada perubahan yang terjadi secara bertahap dari tingkat yang paling rendah ke tingkat yang paling tinggi dan komplek melalui proses maturasi dan pembelajaran.

Perkembangan adalah perubahan yang bersifat kuantitatif dan kualitatif. Perkembangan adalah bertambahnya kemampuan dan keterampilan dalam struktur fungsi tubuh yang lebih kompleks dalam pola yang teratur dan dapat diramalkan, sebagai hasil proses pematangan. Perkembangan menyangkut adanya proses diferensiasi dari sel-sel tubuh, jaringan tubuh, organ-organ, dan sistem organ yang berkembang sedemikian rupa sehingga masing-masing dapat memenuhi fungsinya. Termasuk juga perkembangan emosi, intelektual, dan tingkah laku sebagai hasil interaksi dengan lingkungannya (Soetjiningsih, 2013).

Tahap perkembangan balita berbedabeda berdasarkan umur balita. Menurut Kemenkes RI (2013), tahap perkembangan anak usia 4-5 tahun meliputi Motorik kasar dan halus, seperti: Berdiri 1 kaki 6 detik, melompat-lompat 1 kaki, menari, menggambar tanda silang, menggambar lingkaran, menggambar orang dengan tiga bagian tubuh. Kemampuan berbahasa dan kognitif, seperti: menyebut nama lengkap tanpa dibantu, senang menyebut kata-kata baru, senang bertanya tentang sesuatu, pertanyaan dengan kata-kata yang benar, bicaranya mudah dimengerti, membedakan sesuatu dari ukuran dan bentuknya, menyebut angka, menghitung jari, menyebut namanama hari. Emosi dan psiko-sosial, seperti: bereaksi tenang dan tidak rewel ketika ditinggal ibu. Kemandirian, seperti: berpakaian sendiri tanpa dibantu, menggosok gigi tanpa dibantu.

\section{Analisis Bivariat}

Berdasarkan hasil uji statistik menunjukkan bahwa ada hubungan antara pengetahuan ibu tentang stimulasi dengan perkembangan anak usia 4-5 tahun. Artinya pengetahuan Ibu tentang stimulasi menentukan perkembangan pada anak di PAUD Bina Ana Prasa dan PAUD Islam Baiturrahim. Kategori hubungannya adalah erat. Artinya semakin baik pengetahuan ibu tentang stimulasi, maka anak akan memiliki perkembangan yang sesuai dengan tahap perkembangannnya.

Hal ini sejalan dengan penelitian yang dilakukan oleh Azizah (2012) di TKIT Cahaya Ananda Depok yang menyimpulkan bahwa terdapat hubungan yang bermakna antara pengetahuan tentang stimulasi dengan perkembangan anak. Artinya Ibu yang berpengetahuan baik tentang stimulasi, akan mengetahui adanya keterlambatan dan penyimpangan perkembangan anak dan disarankan kepada ibu untuk dapat melakukan stimulasi pada anak sehinggga dapat berkembang secara optimal.

Penelitian ini juga sejalan dengan penelitian yang dilakukan Nurhasanah (2015) yang menyimpulkan bahwa pengetahuan ibu yang baik akan memberikan hasil yang baik, artinya dengan adanya pengetahuan ibu yang baik tentang stimulasi maka perkembangan anak akan sesuai dengan tahap perkembangannya. Begitu pula sebaliknya, pengetahuan ibu yang kurang akan memberikan efek yang kurang baik terhadap anak. Pengetahuan merupakan modal utama dalam mendidik anak. Ibu mempunyai peran penting di dalam keluarga, terutama dalam proses pembentukan pribadi dan sebagai seorang pendidik bagi anak-anaknya. Artinya semakin baik pengetahuan ibu tentang stimulasi maka semakin baik pula perkembangan pada anak.

Penelitian yang dilakukan di Posyandu RW 06 Rejosari Rejowinangun Kota Gede 
Yogyakarta meng bahwa terdapat hubungan antara pengetahuan ibu dengan perkembangan balita usia 1-5 tahun. Karena pengetahuan tentang stimulasi ibu yang baik sangat erat hubungannya dengan perkembangan anak yang baik dan sebaliknya pengetahuan ibu yang kurang baik membuat perkembangan anak kurang baik dalam tahap perkembangannya (Suhadah, 2015).

Penelitian yang dilakukan Hasrianti (2015) di TK Islam Nurfaidah Balantang Malili Kabupaten Luwu Timur menyimpulkan bahwa ada hubungan bermakna antara pengetahuan ibu tentang stimulasi dengan perkembangan anak usia pra sekolah, apabila pengetahuan ibu mengenai stimulasi anak kurang maka perlakuan ibu untuk memberikan stimulasi kepada anak akan sangat kurang sehingga perkembangan anak tidak terangsang yang akan mengakibatkan keterlambatan perkembangan pada anak, sebaliknya ibu yang memiliki pengetahuan stimulasi baik cenderung memiliki anak dengan tingkat perkembangan yang sesuai dengan tahap perkembangannya.

Pengetahuan tentang stimulasi ini akan membantu orang tua menjadi sadar dan paham mengenai keterlambatan dalam tingkat perkembangan. Hal ini menunjukkan bahwa pengetahuan tersebut akan membawa ibu untuk berpikir dan berusaha supaya anaknya tidak mengalami penyimpangan perkembangan. Dalam komponen ini komponen emosi dan keyakinan ikut bekerja, sehingga ibu berniat akan melakukan stimulasi/rangsangan terhadap perkembangan anak dan pada akhirnya ibu melakukan tindakan stimulasi/rangsangan perkembangan anak (Soetjiningsih, 2013)

Penelitian ini juga sejalan dengan pernyataan Imelda (2015) Ibu sebagai pengasuh terdekat anaknya harus mengetahui lebih banyak mengenai stimulasi perkembangan. Semakin rendah tingkat pengetahuan ibu tentang stimulasi maka anak memiliki resiko akan mengalami dugaan keterlambatan dalam tahap perkembangan.

\section{KESIMPULAN}

1. Dari $52 \mathrm{ibu}$, terdapat $21 \mathrm{ibu}(40,4 \%)$ yang berpengetahuan baik di PAUD Bina Ana Prasa dan PAUD Islam Baiturrahim Kabupaten Rejang Lebong.

2. Dari $52 \mathrm{ibu}$, terdapat $31 \mathrm{Ibu}(59,6 \%)$ yang memiliki anak dengan perkembangan yang sesuai dengan tahap perkembangan di PAUD Bina Ana Prasa dan PAUD Islam Baiturrahim Kabupaten Rejang Lebong.

3. Ada hubungan yang signifikan pengetahuan ibu tentang stimulasi dengan perkembangan anak usia 4-5 tahun di PAUD Bina Ana Prasa dan PAUD Islam Baiturrahim Kabupaten Rejang Lebong dengan katagori hubungan yang erat.

\section{SARAN}

1. Bagi PAUD Bina Ana Prasa dan PAUD Islam Baiturrahim.

Agar selalu dapat meningkatkan kualitas pelayanan, khususnya pemantauan perkembangan balita dengan upaya mengaplikasikan deteksi dini penyimpangan perkembangan anak secara rutin. Karena balita pada masa perkembangannya perlu mendapatkan perhatian yang lebih baik dari orang tua, para pembimbing, dan pendidik sekolah.

\section{Bagi Peneliti Lain}

Diharapkan pada peneliti lain dapat melakukan penelitian lebih lanjut dengan menggunakan variabel bebas lain yang berhubungan dengan perkembangan anak, antara lain pendidikan dan pekerjaan.

\section{DAFTAR PUSTAKA}

Azizah, N.N. 2012. Gambaran Stimulasi Perkembangan Oleh Ibu Terhadap Anak Pra Sekolah di TKIT Cahaya Ananda Depok. Skripsi. Depok : Fakultas Ilmu Keperawatan Universitas Indonesia. Diunduh dari : http://lib.ui.ac.id/file? file= $\operatorname{digital} / 20312827-$ S43592- 
Gambaran\%20stimulasi.pdf.

Dinkes Kabupaten Rejang Lebong. 2018. Profil Dinas Kesehatan Kabupaten Rejang Lebong Tahun 2018. Rejang Lebong: Dinkes Kabupaten Rejang Lebong

Hotmaria, Y. 2010. Hubungan Pengetahuan Ibu Tentang Stimulasi Perkembangan dengan Perkembangan Anak Usia 3-5 Tahun di Kelurahan Kwala Bekala. Jakarta: Skripsi Fakultas Keperawatan Universitas Sumatera Utara. Diunduh dari

http://repository.usu.ac.id/handle/12345 6789/20589.

Hasrianti. 2012. Hubungan Pengetahuan Ibu Tentang Stimulasi Bermain dengan Perkembangan Motorik Kasar Pada Usia Pra Sekolah di TK Islam Nurfaidah Balantang Malili Kabupaten Luwu Timur. Makassar: Skripsi Fakultas Ilmu Kesehatan UIN Alaudin Makassar. Diunduh dari : http://repositori.uinalauddin.ac.id/3414/.

Imelda. 2017. Hubungan Pengetahuan Ibu Dengan Perkembangan Anak Pra Sekolah Usia 3- 5 Tahun di Banda Aceh. Idea Nursing Journal, VIII (30). Diunduh dari http://www.jurnal.unsyiah.ac.id/INJ/arti cle/download/9487/7946.

Kemenkes RI. 2018. Pedoman Pelaksanaan Stimulasi, Deteksi dan Intervensi Dini Tumbuh Kembang Anak Ditingkat Pelayanan Kesehatan Dasar. Jakarta: Kemenkes RI.

Kemenkes RI. 2013. Pedoman Pelaksanaan Stimulasi, Deteksi, dan Intervensi Dini Tumbuh Kembang Anak di Tingkat Pelayanan Kesehatan Dasar. Jakarta : Kemenkes RI.

Kemenkes RI. 2010. Pedoman Pelaksanaan Stimulasi, Deteksi, dan Intervensi Dini Tumbuh Kembang Anak di Tingkat Pelayanan Kesehatan Dasar. Jakarta : Kemenkes RI.

Kusuma. 2012. Hubungan Pengetahuan Ibu dengan Perkembangan Motorik Halus Balita di Wilayah Kerja Puskesmas
Penumping Surakarta Tahun 2012. Diunduh dari : http://eprints.ums.ac.id/18580/19/Naska h_publikasi.pdf.

Notoatmodjo, S. 2007. Kesehatan Masyarakat Ilmu dan Seni. Jakarta : PT. Rineka Cipta.

Nurhasanah. 2015. Hubungan Tingkat Pengetahuan Ibu tentang Stimulasii dengan Perkembangan Motorik Anak Usia 1-3 Tahun di Posyandu Teratai I Desa Bangunjiwo. Yogyakarta. Skripsi STIKES Aisyah Yogyakarta. Diunduh dari http://digilib.unisayogya.ac.id/677/.

Septiari, B.B. 2012. Mencetak Balita Cerdas dan Pola Asuh Orang Tua. Yogyakarta : Nuha Medika.

Suhadah. 2015. Hubungan Pengetahuan Ibu tentang Stimulasi dengan Perkembangan Balita di Posyandu RW 6 Rejosari Rejowinangun Kotogede Yogyakarta. Yogyakarta : Skripsi STIKES Aisyah Yogyakarta. Diunduh dari

http://digilib.unisayogya.ac.id/763/1/N ASKAH\%20PUBLIKASI.pdf.

Sulistyawati, A. 2014. Deteksi Tumbuh Kembang Anak. Jakarta : Salemba Medika.

Soetjiningsih. 2013. Tumbuh Kembang Anak. Edisi 1. Jakarta : EGC. 